\title{
Antimicrobial resistance in patients with decompensated liver cirrhosis and bacterial infections in a tertiary center in Northern Germany
}

\author{
Annika Hillert ${ }^{1}$, Marie Schultalbers ${ }^{1}$, Tammo L. Tergast ${ }^{1}$, Ralf-Peter Vonberg ${ }^{2,4}$, Jessica Rademacher ${ }^{3,4}$, \\ Heiner Wedemeyer ${ }^{1}$, Markus Cornberg ${ }^{1,5,7}$, Stefan Ziesing ${ }^{2}$, Benjamin Maasoumy ${ }^{1,5^{*}}$ and \\ Christoph Höner zu Siederdissen ${ }^{1,6^{*}}$
}

\begin{abstract}
Background and aims: Bacterial infections are common in patients with decompensated liver cirrhosis and a leading cause of death. Reliable data on antibiotic resistance are required to initiate effective empiric therapy. We here aim to assess the antimicrobial resistance profile of bacteria among patients with liver cirrhosis and infection.

Methods: Overall, 666 cirrhotic patients admitted to Hannover Medical School between January 2012 and April 2018 with ascites were assessed for bacterial infection. In case of infection, bacteria cultured from microbiological specimens of ascites, blood or urine were identified and analyzed for resistances against common antibiotic agents. Furthermore, analyses compared two periods of time and community-acquired vs. nosocomial infections.

Results: In 281 patients with infection, microbiological sampling was performed and culture-positive results were obtained in 56.9\%. Multidrug-resistant (MDR)-bacteria were found in 54 patients (19.2\%). Gram-positive organisms were more common $(n=141 / 261,54.0 \%)$ and detected in $116 / 192$ culture-positive infections (60.4\%). Comparing infections before and after 2015, a numerical decline for MDR-bacteria ( $23.8 \%$ vs. $15.6 \%, p=0.08$ ) was observed with a significant decline in meropenem resistance (34.9\% vs. $19.5 \%, p=0.03)$. MDR-bacteria were more frequent in the case of nosocomial infections. Of note, in ascites the majority of the tested bacteria were resistant against ceftriaxone (73.8\%) whereas significantly less were resistant against meropenem (27.0\%) and vancomycin (25.9\%).
\end{abstract}

Conclusions: In our tertiary center, distinct ratios of gram-positive infection with overall low ratios of MDR-bacteria were found. Adequate gram-positive coverage in the empiric therapy should be considered. Carbapenem treatment may be omitted even in nosocomial infection. In contrast, 3rd generation cephalosporins cannot be recommended even in community-acquired infection in our cirrhotic population.

Keywords: Liver cirrhosis, Ascites, Antibiotic resistance, Bacterial infection, Multiresistant bacteria

*Correspondence: Maasoumy.benjamin@mh-hannover.de; Hoenerzusiederdissen.christoph@mh-hannover.de

${ }^{1}$ Department for Gastroenterology, Hepatology and Endocrinology, Hannover Medical School, Carl-Neuberg-Str. 1, 30625 Hannover, Germany Full list of author information is available at the end of the article

\begin{abstract}
Introduction
Bacterial infections increase the mortality of patients with liver cirrhosis up to four times [1] and are one of the leading causes of death in this population [2]. Particular hazards are numerous consecutive nosocomial infections decreasing liver transplant-free survival significantly [3].
\end{abstract}

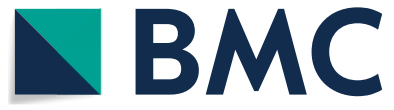

(c) The Author(s) 2021. Open Access This article is licensed under a Creative Commons Attribution 4.0 International License, which permits use, sharing, adaptation, distribution and reproduction in any medium or format, as long as you give appropriate credit to the original author(s) and the source, provide a link to the Creative Commons licence, and indicate if changes were made. The images or other third party material in this article are included in the article's Creative Commons licence, unless indicated otherwise in a credit line to the material. If material is not included in the article's Creative Commons licence and your intended use is not permitted by statutory regulation or exceeds the permitted use, you will need to obtain permission directly from the copyright holder. To view a copy of this licence, visit http://creativecommons.org/licenses/by/4.0/. The Creative Commons Public Domain Dedication waiver (http://creativeco $\mathrm{mmons}$.org/publicdomain/zero/1.0/) applies to the data made available in this article, unless otherwise stated in a credit line to the data. 
The most frequent sites of infection are spontaneous bacterial peritonitis (SBP) and urinary tract infections (UTI) [2-4]. Patients with liver cirrhosis have a higher susceptibility for infections resulting in an increased risk for sepsis and sepsis-related mortality [5]. Early empiric antibiotic treatment can decrease the mortality of severe sepsis and is strongly recommended [6-10].

In 2018 the European Association for the Study of the Liver (EASL) published a guideline for the management of patients with decompensated cirrhosis [11]. Empirical antibiotic treatment recommendations for communityacquired SBP and bloodstream infection (BSI) are 3rd generation cephalosporins and meropenem for nosocomial SBP and BSI. Treatment recommendations for UTI include ciprofloxacin or nitrofurantoin. In addition, it is recommended to consider the local resistance profiles $[11,12]$. The EASL guideline distinguishes between countries with high and low ratios of bacterial resistance [11].

International studies with individual data for single countries and regions show a prevalence of multidrugresistant (MDR)-bacteria in patients with cirrhosis in Germany between 26\% [13] and 34.1\% [14] of culturepositive patients. Importantly, the prevalence varies significantly between local regions, e.g., $4.2 \%$ and $41.2 \%$ [14].

Antibiotic therapy is challenged by several trends. An increasing number of gram-positive pathogens can be found in patients with SBP $[4,15,16]$ which makes 3rd generation cephalosporins less effective [17]. Additionally, due to frequent hospitalization and regular use of antibiotics in patients with liver cirrhosis, cirrhotic patients have a higher risk for developing infections caused by MDR-bacteria [18]. Those infections are associated with a higher incidence of treatment failure, septic shock, and hospital mortality ][13, 14, 18] and are increasing dramatically according to several studies $[4$, $18,19]$.

The EASL recommendations for the antibiotic treatment of patients with liver cirrhosis are based on panEuropean studies on pathogens and their antibiotic resistance and aim to provide valid recommendations across Europe. However, given the changing epidemiology of pathogens and resistances as well as local regional differences, it may be better to rely on local data than global recommendations.

With the present study, we aim to present a big database of frequently found pathogens and their resistances in microbiology samples taken during SBP, BSI, and UTI from patients with decompensated cirrhosis and question whether the EASL recommendations are adequate in our region. In addition, further analyses distinguish between two periods of time to assess trends in MDR-infection and between community-acquired vs. nosocomial infections. Based on these findings we aim to provide empiric treatment recommendations for our tertiary center in Northern Germany.

\section{Material and methods \\ Patient cohort}

The patients were recruited from the Hannover Ascites Cohort, which considered all consecutive patients with liver cirrhosis who underwent paracentesis during their hospital stay at the Hannover Medical School between January 2012 and April 2018. The patients were automatically identified retrospectively by the Enterprise Clinical Research Data Warehouse (ECRDW) to minimize a potential selection bias. Overall, 1314 patients were screened and 666 patients were included after manual assessment of the patient's charts (Fig. 1). Routine laboratory data were collected using the ECRDW. Routine clinical data including the date of infection and antibiotic susceptibility testing (AST) results were collected manually from the patients' files. Diagnosis of liver cirrhosis was based on ultrasound, FibroScan $(\geq 14.5 \mathrm{kPa})$, biochemical results, and/or liver biopsy.

Exclusion criteria were lack of evidence of cirrhosis, extrahepatic malignancy, hepatocellular carcinoma beyond the Milan criteria, secondary intraabdominal inflammation, infection with HIV, congenital immune dysfunction, non-liver organ transplantation, lack of data, and absence of written informed consent.

\section{Ethics}

The local ethics committee of Hannover Medical School approved the study (ethic no. 7935_BO_K_2018 from June 22nd 2018) and patients provided written informed consent for the scientific use of their clinical data. The

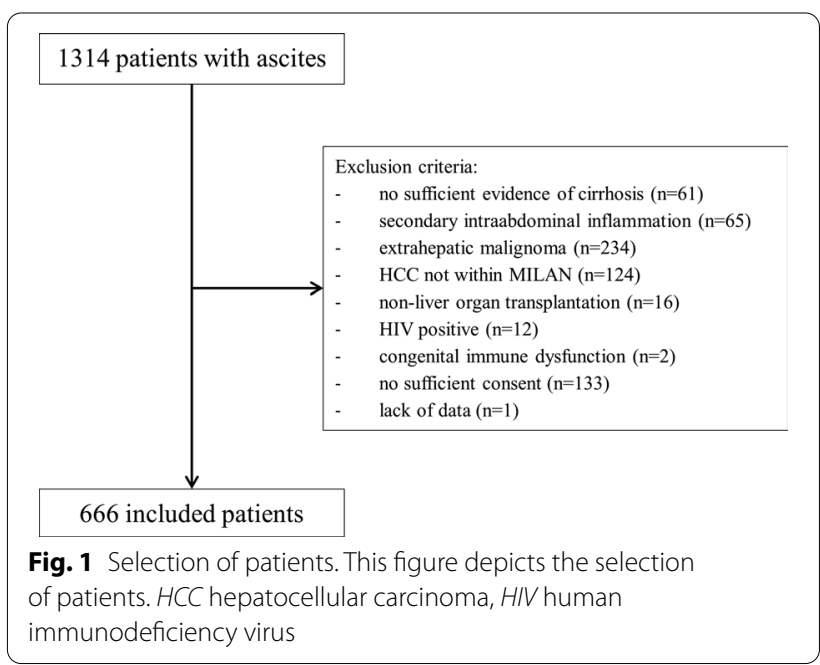


study was conducted according to the Declaration of Helsinki.

\section{Data assessment}

The observation period included the complete hospital stay until discharge, transfer to another hospital or nursing home, liver transplantation, or death. Infections were diagnosed by the attending physician or in case of uncertainty by infectiologists (BM, MC, JR, CHZS) based on clinical symptoms and the following laboratory results:

- SBP: $\geq 500$ nuclei containing cells/ $\mu$ l ascites fluid [20]

- BSI: positive blood cultures

- UTI: leukocyturia and/or positive urine cultures with significant germination number $\left(\geq 10^{5} \mathrm{CFU} / \mathrm{ml}\right.$ urine).

In this study, ascites and blood were considered sterile. Therefore, all the pathogens found in ascites or blood during infection were included in the analyses. Pathogens found in urine during infection were only included if at least $10^{5} \mathrm{CFU} / \mathrm{ml}$ urine were detected except for Escherichia coli according to local guidelines [21].

Infection was classified based on the time from admission as community-acquired $(<48 \mathrm{~h})$ or nosocomial $(>48 \mathrm{~h})$ [22]. If the patient was hospitalized within the previous three months, infections in the first $48 \mathrm{~h}$ after admission were classified as nosocomial.

Pathogens were counted once per site and patient only. In case, a pathogen was redetected, only the first Antimicrobial Susceptibility Testing was included in our study. For easier reading, a sample with a detected pathogen is called positive.

The AST was evaluated according to European Committee on Antimicrobial Susceptibility Testing (EUCAST) international guidelines and expert microbiologists (RV, SZ). Resistant results include intrinsic resistances as well as acquired resistances. Intermediate results were stated as resistant.

Definitions for multiresistant bacteria are not consistent. For better distinction the existence of one of the following resistances classified the pathogen as severe resistant:

- Vancomycin- or Linezolid-resistant Enterococcus

- Oxacillin-/Methicillin-resistant Staphylococcus aureus (ORSA/MRSA)

- Multiresistant gram-negative germ (3MRGN/4MRGN) according to the recommendation of the German commission of hospital hygiene and infection prevention (KRINKO) [23] (Additional file 1: Table 1).
Enterobacteriaceae, Staphylococcus aureus, Enterococcus spp., and Acinetobacter spp. were classified as multidrug-resistant (MDR) if the isolate is non-susceptible to at least 1 agent in $\geq 3$ antimicrobial categories [24]. In our study, all pathogens with a severe resistance met MDRcriteria as well. Additional file 2: Table 2 shows the antimicrobial categories and agents used for the definition of MDR.

\section{Study design}

Three main analyses are part of this study. In the first analysis, the development of antibiotic resistance over time was observed. For this part, the cohort was divided into two groups. The first one ("period 1") contains the samples that were taken during an infection between January 1st 2012 and December 31st 2014. The second period ("period 2") includes the samples that were taken between January 1st 2015 and April 30th 2018. The analysis compares the number of severe resistances, MDR, and the ratios of resistances against common antibiotics.

The second analysis presents the ratios of bacteria with resistance against common antibiotics in SBP, BSI, and UTI. In a further analysis, these samples are subdivided into community-acquired and nosocomial infections.

The third analysis evaluates the treatment options for SBP, BSI and UTI recommended by EASL. For this part, we analyzed the ratios of patients with resistance against the recommended antibiotics in mono- and combination-therapy. Suboptimal antibiotic selection was assumed in patients if at least one pathogen was resistant to all applied antibiotic agents.

\section{Statistics}

Statistical analyses were performed with SPSS (IBM SPSS Statistics 26). Continuous data were analyzed with unpaired t-test and categorical data with Fisher's exact test.

\section{Results}

\section{Baseline characteristics}

Overall, 666 patients were included in this study. The majority $(64.3 \%)$ was male and the median age was 56.7 (17-87) years. The major causes of liver cirrhosis were alcohol (50.5\%) and hepatitis C virus infection (13.8\%) with a median MELD-Score of 17.6. In half of the patients, at least one infection was diagnosed. The most common infection was SBP followed by UTI and BSI (Table 1).

Microbiological sampling was performed in 281 patients, $56.9 \%$ of them had at least one culture-positive sample. Samples, in which more than one pathogen was 
Table 1 Patients' characteristics

\begin{tabular}{|c|c|c|c|c|c|}
\hline Variable & All patients & Sampled patients*1 & $\begin{array}{l}\text { Period } 1(01 / 2012- \\
12 / 2014)^{* 1}\end{array}$ & $\begin{array}{l}\text { Period } 2(01 / 2015- \\
04 / 2018)^{* 1}\end{array}$ & $p$ value ${ }^{* 2}$ \\
\hline Total number of patients & 666 & 280 & 126 & 155 & \\
\hline \multicolumn{6}{|l|}{ Sex } \\
\hline Female $(n, \%)$ & $238(35.7 \%)$ & $97(34.6 \%)$ & $44(34.9 \%)$ & $53(34.4 \%)$ & 0.93 \\
\hline Male (n, \%) & $428(64.3 \%)$ & $183(65.4 \%)$ & $82(65.1 \%)$ & $101(65.6 \%)$ & 0.93 \\
\hline Age (years) & $56.7(17-87)$ & $57.3(17.8-85.8)$ & $56.9(21.5-81)$ & $57.7(17.8-85.8)$ & 0.54 \\
\hline Days in hospital & $15.5(1-126)$ & $23.0(1-126)$ & $24.5(2-97)$ & $22.0(1-126)$ & 0.11 \\
\hline 90-day mortality*3 & $148(22.2 \%)$ & $89(31.8 \%)$ & $38(30.2 \%)$ & $51(33.1 \%)$ & 0.60 \\
\hline \multicolumn{6}{|l|}{ Etiology of liver cirrhosis ${ }^{* 4}$} \\
\hline Alcohol-related (n, \%) & $336(50.5 \%)$ & $130(46.4 \%)$ & $56(44.4 \%)$ & $74(48.1 \%)$ & 0.54 \\
\hline $\operatorname{HCV}(n, \%)$ & $92(13.8 \%)$ & $37(13.2 \%)$ & $20(15.9 \%)$ & $17(11.0 \%)$ & 0.24 \\
\hline $\operatorname{HBV}(n, \%)$ & $29(4.4 \%)$ & $10(3.6 \%)$ & $4(3.2 \%)$ & $6(3.9 \%)$ & 0.75 \\
\hline $\mathrm{NASH}(\mathrm{n}, \%)$ & $45(6.8 \%)$ & $27(9.6 \%)$ & $11(8.7 \%)$ & $16(10.4 \%)$ & 0.77 \\
\hline Other $(n, \%)$ & $226(33.9 \%)$ & $102(36.4 \%)$ & $45(35.7 \%)$ & $57(37.0 \%)$ & 0.82 \\
\hline \multicolumn{6}{|l|}{ Laboratory values at admission } \\
\hline MELD & $17.6(6.43-40)$ & $19.8(7.9-40.0)$ & $19.2(8.6-40.0)$ & $19.9(7.9-40.0)$ & 0.41 \\
\hline INR & $1.42(0.97-5.64)$ & $1.5(1.0-5.6)$ & $1.5(1.1-3.4)$ & $1.5(1.0-5.6)$ & 0.09 \\
\hline Creatinine $(\mu \mathrm{mol} / \mathrm{l})$ & $109.5(30-878)$ & $124.0(32.0-878.0)$ & $116.0(40.0-691.0)$ & $126.0(32.0-878.0)$ & 0.52 \\
\hline Thrombocytes $\left(\times 10^{3} / \mu \mathrm{l}\right)$ & $117(15-813)$ & $113.5(15.0-813.0)$ & $110.5(15.0-490.0)$ & $123.0(17.0-813.0)$ & 0.28 \\
\hline $\mathrm{CRP}(\mathrm{mg} / \mathrm{l})$ & $24(0.4-433)$ & $28.1(0.9-433.0)$ & $26.0(2.0-433.0)$ & $30.8(0.9-266.0)$ & 0.78 \\
\hline Bilirubin $(\mu \mathrm{mol} / \mathrm{l})$ & $42(3-786)$ & $54.0(3.0-786.0)$ & $54.0(4.0-786.0)$ & $54.0(3.0-676.0)$ & 0.85 \\
\hline Sodium (mmol/l) & $134(115-149)$ & $134.0(115.0-149.0)$ & $134.0(117.0-145.0)$ & $134.0(115.0-149.0)$ & 0.95 \\
\hline Leucocytes $\left(\times 10^{3} / \mu \mathrm{l}\right)$ & $7.6(1.1-83.4)$ & $8.5(1.9-83.4)$ & $8.6(2.3-83.4)$ & $8.5(1.9-35.5)$ & 0.90 \\
\hline Patients with SBP $(n, \%)$ & $262(39.3 \%)$ & 205 (73.2\%) & 91 (72.5\%) & $114(77.3 \%)$ & 0.74 \\
\hline Patients with BSI $(n, \%)$ & $49(7.4 \%)$ & $49(17.5 \%)$ & $28(22.2 \%)$ & $21(13.6 \%)$ & 0.06 \\
\hline Patients with UTI $(n, \%)$ & $153(23.0 \%)$ & $93(33.2 \%)$ & $37(29.4 \%)$ & $56(36.4 \%)$ & 0.22 \\
\hline $\begin{array}{l}\text { Patients with at least one infec- } \\
\text { tion }(n, \%)\end{array}$ & $354(53.2 \%)$ & & & & \\
\hline $\begin{array}{l}\text { Patients with one of the three } \\
\text { infection }(n, \%)\end{array}$ & $256(38.4 \%)$ & 219 (78.2\%) & 100 (79.4\%) & $119(77.3 \%)$ & 0.67 \\
\hline $\begin{array}{l}\text { Patients with two of the three } \\
\text { infections }(n, \%)\end{array}$ & $86(12.9 \%)$ & $55(19.6 \%)$ & $22(17.5 \%)$ & $33(21.4 \%)$ & 0.41 \\
\hline $\begin{array}{l}\text { Patients with all three infec- } \\
\text { tions }(n, \%)\end{array}$ & $12(1.8 \%)$ & $6(2.1 \%)$ & $4(3.2 \%)$ & $2(1.3 \%)$ & 0.28 \\
\hline $\begin{array}{l}\text { Patients with microbiological } \\
\text { sampling during infection } \\
(n, \%)\end{array}$ & $281(42.2 \%)$ & & & & \\
\hline $\begin{array}{l}\text { Patients with at least one posi- } \\
\text { tive microbiological sample } \\
(n, \%)\end{array}$ & 160 (24.0\%) & 159 (56.8\%) & 76 (60.3\%) & 83 (53.9\%) & 0.28 \\
\hline
\end{tabular}

\footnotetext{
*1Only patients with microbiological sampling during infection included. One patient was excluded because the time of his infection overlapped the cutoff date for both periods

${ }^{* 2}$ Comparison of the two groups "period 1" and "period 2"

${ }^{*}$ The 90 days were counted starting from the end of hospitalization

*470 patients (32 sampled patients, 14 in period 1, 18 in period 2) had more than one etiology of cirrhosis

Categorical variables are expressed as the number and percentage of the total study group or subgroup. Continuous variables are expressed as median and range $H C V$ hepatitis $C$ virus, HBV hepatitis B virus, NASH nonalcoholic steatohepatitis, MELD model for end-stage liver disease, INR International normalized ratio of prothrombin time, CRPC-reactive protein, SBP spontaneous bacterial peritonitis, BSI bloodstream infection, UTI urinary tract infection; $\mathrm{n}$, number of patients
}

detected, were found in 46 patients (16.4\%). Pathogens with severe resistance as defined above were found in twelve patients (4.3\%). MDR-bacteria were found in 54 patients (19.2\%). 


\section{Frequency of pathogens}

Overall, 261 pathogens were found in 192 culture-positive infections of 160 patients. If pathogens were detected at more than one site of a patient, the detected species were the same in $60.0 \%$ of the patients with SBP and BSI $(n=6 / 10), 15.4 \%$ of the patients with SBP and UTI $(n=2 / 13), 28.6 \%$ of patients with BSI and UTI $(n=4 / 14)$ and $20.0 \%$ of patients with evidence of infection at all three infection sites $(n=1 / 5)$. Fifty-four infections were polymicrobial, most commonly containing E. faecalis $(31.5 \%, \mathrm{n}=17)$, E. faecium $(24.1 \%, \mathrm{n}=13)$, E. coli $(22.2 \%$, $\mathrm{n}=12)$ and $S$. aureus $(14.8 \%, \mathrm{n}=8)$ (Additional file 3: Table 3).

The most frequent pathogen was Escherichia coli. The second and third most frequent pathogens were the gram-positive pathogens Enterococci and Staphylococci. Of note, more than half of the detected pathogens were gram-positive organisms $(n=141$ of $261,54.0 \%)$, found in 116 of 192 culture-positive infections (60.4\%). Of all Enterobacteriaceae found in the samples, 49.1\% $(\mathrm{n}=28 / 57)$ were classified as MDR, and $16.7 \%(\mathrm{n}=1 / 6)$ of Acinetobacter spp. Of the 28 Staphylococcus aureus $35.7 \%(\mathrm{n}=10)$ were classified as MDR (MRSA) and 38.9\% $(\mathrm{n}=21 / 54)$ of Enterococcus spp. In total, $23.0 \%$ $(n=60 / 261)$ of all detected pathogens were MDR, 23.3\% of them $(n=14 / 60)$ had a severe resistance (Table 2$)$.

\section{Changes in antibiotic resistance over time}

To assess the development of antibiotic resistance over time, all 280 patients were compared depending on the date of infection. One hundred and twenty-six patients were allotted for period 1 (2012-2015) and 154 patients for period 2 (2015-2018). The baseline parameters of the two study groups are depicted in Table 1 .

In both periods more than half of the patients had at least one positive sample $(60.3 \%$ in period 1 vs. $53.9 \%$ in period $2, p=0.28)$. In period 2 less patients had MDRbacteria $(23.8 \%$ vs. $15.6 \%, p=0.08)$ (Fig. $2 \mathrm{a})$. The ratio of patients with severe resistances was slightly higher in period 1 compared to period $2(5.6 \%$ vs. $3.2 \%, p=0.34)$ (Fig. 2b). Across the tested antibiotics, no major shift in resistances could be confirmed, except for meropenem

Table 2 Most frequent pathogens.

\begin{tabular}{|c|c|c|c|c|}
\hline \multirow[t]{2}{*}{ Pathogen } & \multicolumn{4}{|c|}{ No. (\%) of pathogens } \\
\hline & $\begin{array}{l}\text { Total } \\
(n=261)\end{array}$ & $\begin{array}{l}\text { Ascites } \\
(n=90)\end{array}$ & $\begin{array}{l}\text { Blood } \\
(n=63)\end{array}$ & $\begin{array}{l}\text { Urine } \\
(n=108)\end{array}$ \\
\hline \multicolumn{5}{|l|}{ Gram-negative organisms } \\
\hline All & $67(25.7)$ & $21(23.3)$ & $17(27.0)$ & 29 (26.9) \\
\hline Escherichia coli & $35(13.4)$ & $13(14.4)$ & $6(9.5)$ & $16(14.8)$ \\
\hline Klebsiella pneumoniae & $14(5.4)$ & $4(4.4)$ & $5(7.9)$ & $5(4.6)$ \\
\hline Other & $18(6.9)$ & $4(4.4)$ & $6(9.5)$ & $8(7.4)$ \\
\hline \multicolumn{5}{|l|}{ Gram-positive organisms } \\
\hline All & $141(54.0)$ & $65(72.2)$ & $42(66.7)$ & $34(31.5)$ \\
\hline Staphylococcus aureus & $28(10.7)$ & $14(15.6)$ & $11(17.5)$ & $3(2.8)$ \\
\hline Enterococcus faecalis & $27(10.3)$ & $6(6.7)$ & $4(6.3)$ & $17(15.7)$ \\
\hline Enterococcus faecium & $23(8.8)$ & $9(10.0)$ & $6(9.5)$ & $8(7.4)$ \\
\hline Staphylococcus epidermidis & $23(8.8)$ & $7(7.8)$ & $14(22.2)$ & $2(1.9)$ \\
\hline Staphylococcus haemolyticus & $10(3.8)$ & $8(8.9)$ & $2(3.2)$ & $0(0.0)$ \\
\hline Other & $30(11.5)$ & $21(23.3)$ & $5(7.9)$ & $4(3.7)$ \\
\hline \multicolumn{5}{|l|}{ Fungi } \\
\hline All & $42(16.1)$ & $4(4.4)$ & $4(6.3)$ & $34(31.5)$ \\
\hline Candida albicans & $21(8.0)$ & $2(2.2)$ & $2(3.2)$ & $17(15.7)$ \\
\hline Other & $21(8.0)$ & $2(2.2)$ & $2(3.2)$ & $17(15.7)$ \\
\hline Other & $11(4.2)$ & $0(0.0)$ & $0(0.0)$ & $11(10.2)$ \\
\hline \multicolumn{5}{|l|}{ Multidrug-resistant bacteria (MDR-bacteria) } \\
\hline All & $60(23.0)$ & $22(24.4)$ & $14(22.2)$ & $24(22.2)$ \\
\hline Multiresistant gram-negative germ (3MRGN) & $6(2.3)$ & $1(1.1)$ & $1(1.6)$ & $4(3.7)$ \\
\hline $\begin{array}{l}\text { Oxacillin-/methicillin-resistant Staphylococcus aureus } \\
\text { (ORSA/MRSA) }\end{array}$ & $5(1.9)$ & $2(2.2)$ & $2(3.2)$ & $1(0.9)$ \\
\hline Vancomycin-resistant Enterococcus & $2(0.8)$ & $0(0.0)$ & $0(0.0)$ & $2(1.9)$ \\
\hline Linezolid-resistant Enterococcus & $1(0.4)$ & $0(0.0)$ & $0(0.0)$ & $1(0.9)$ \\
\hline
\end{tabular}




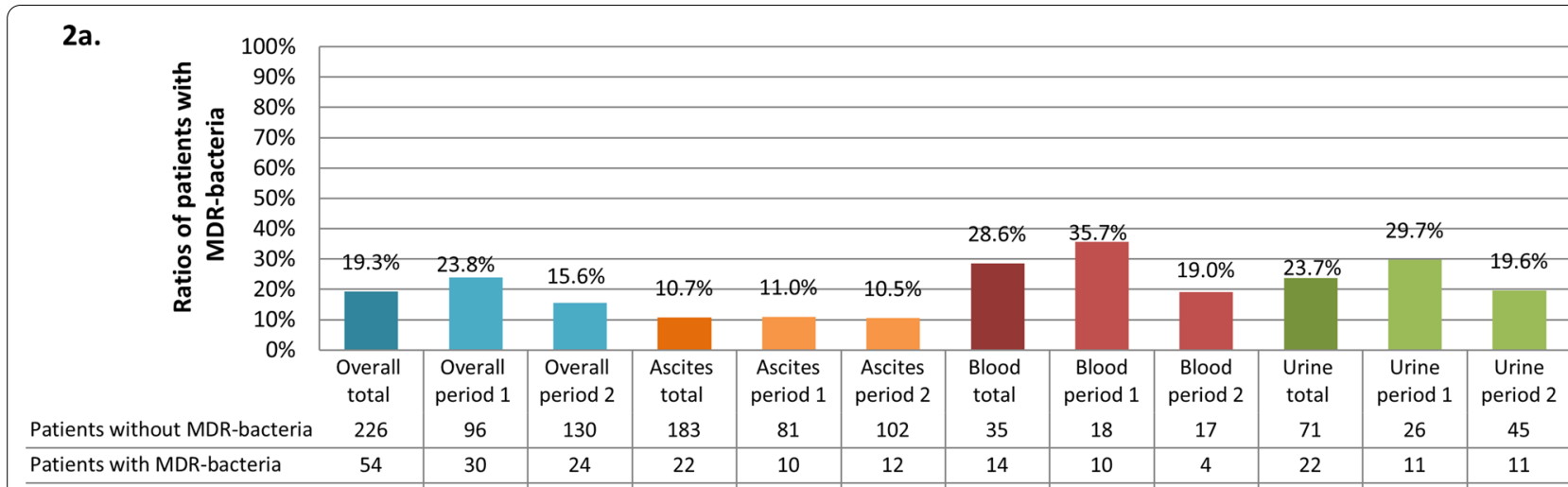

2b.

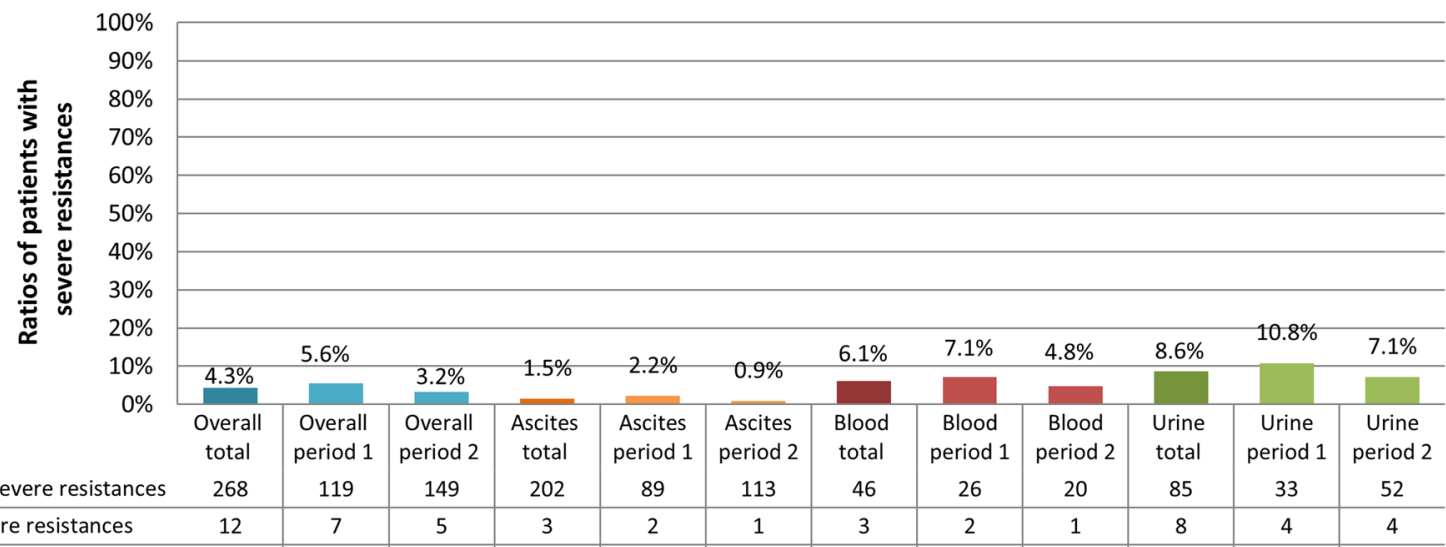

Patients without severe resistances

Patients with severe resis

Fig. 2 Ratios of patients with MDR-bacteria (a) and bacteria with severe resistances (b). a Presents the ratios of patients with MDR-bacteria. $\mathbf{b}$ Shows the ratio of patients with severe resistances. The group "overall" does not comply with the sum of the subgroups, because some patients had more than one infection. MDR: multidrug-resistance

resistance, which significantly decreased $(34.9 \%$ vs. $19.5 \%, p=0.03$ ) (Table 3).

\section{Antibiotic resistance in common locations for infection}

Pathogens were detected in more than half of the urine samples taken during UTI $(66.9 \%, \mathrm{n}=83 / 124)$ and blood cultures taken during BSI $(56.1 \%, \mathrm{n}=55 / 98)$ but in less than a quarter of ascites samples taken during SBP $(23.2 \%, n=72 / 310)$. The highest ratio of MDR-bacteria was detected in ascites samples (ascites: $24.4 \%, \mathrm{n}=22 / 90$; urine: $22.2 \%, n=24 / 108$; blood: $22.2 \%, n=14 / 63$ ). Pathogens with severe resistance were more likely found in urine samples $(7.4 \%, \mathrm{n}=8 / 108$; blood: $4.8 \%, \mathrm{n}=3 / 63$; ascites: $3.3 \%, \mathrm{n}=3 / 90$ ) (Additional file 4: Table 4).

Table 4 shows the AST results for commonly used antibiotics for the three different types of infection. In ascites the majority of the tested bacteria were resistant against ceftriaxone (73.8\%), whereas only around a quarter was resistant against meropenem $(27.0 \%)$ and vancomycin (25.9\%). Piperacillin/tazobactam showed similar effectiveness as meropenem with only $34.5 \%(n=29 / 55)$ of the tested bacteria being resistant. Bacteria found in blood were slightly more resistant to commonly used antibiotics. In urine, 23 of the detected pathogens had resistances against at least four antibiotics commonly used for UTI (susceptibility and resistances for distinct antibiotics and combinations are depicted in Table 4).

For further analyses, the SBP and UTI cohorts were divided into community-acquired and nosocomial infections. This separation was not possible for BSI, because only three patients had a community-acquired infection. In ascites the ratio of patients with positive cultures was significantly higher in nosocomial SBP versus community-acquired infection ( $36.9 \%$ vs. $20.0 \%, p=0.04)$. MDR-bacteria were slightly more frequent in nosocomial episodes $(11.5 \%$ vs. $7.5 \%, p=0.46)$. In addition, bacteria with severe resistances were only found in patients with nosocomial episodes of SBP. Similarly, for UTI the patients with nosocomial infections were more likely to have positive cultures compared with communityacquired UTI $(79.5 \%$ vs. $72.7 \%, p=0.61)$. Moreover, MDR-bacteria were also more frequent in patients with nosocomial UTI ( $24.1 \%$ vs. $18.2 \%, p=0.66)$. However, patients with severe resistant pathogens were found 
Table 3 Susceptibility of pathogens in period 1 and period 2

\begin{tabular}{|c|c|c|c|c|c|c|c|c|c|}
\hline \multirow{3}{*}{$\begin{array}{l}\text { Antibiotic agent } \\
\text { Overall }\end{array}$} & \multicolumn{4}{|c|}{ Period $1(01 / 2012-12 / 2014)$} & \multicolumn{4}{|c|}{ Period $2(01 / 2015-04 / 2018)$} & \multirow[t]{3}{*}{$p$ value } \\
\hline & \multicolumn{2}{|c|}{ Susceptible } & \multicolumn{2}{|c|}{ Resistant } & \multicolumn{2}{|c|}{ Susceptible } & \multicolumn{2}{|c|}{ Resistant } & \\
\hline & n & $\%$ & $\mathrm{n}$ & $\%$ & $\mathrm{n}$ & $\%$ & $\mathrm{n}$ & $\%$ & \\
\hline Ampicillin & 31 & 34.4 & 59 & 65.6 & 33 & 32.4 & 69 & 67.6 & 0.76 \\
\hline Ceftriaxone & 32 & 34.0 & 62 & 66.0 & 26 & 26.0 & 74 & 74.0 & 0.22 \\
\hline Ciprofloxacin & 33 & 62.3 & 20 & 37.7 & 48 & 68.6 & 22 & 31.4 & 0.47 \\
\hline Meropenem & 56 & 65.1 & 30 & 34.9 & 62 & 80.5 & 15 & 19.5 & 0.03 \\
\hline \multicolumn{10}{|l|}{ Ascites } \\
\hline Ampicillin & 15 & 41.7 & 21 & 58.3 & 14 & 29.8 & 33 & 70.2 & 0.26 \\
\hline Ceftriaxone & 13 & 36.1 & 23 & 63.9 & 8 & 18.2 & 36 & 81.8 & 0.07 \\
\hline Ciprofloxacin & 13 & 68.4 & 6 & 31.6 & 23 & 63.9 & 13 & 36.1 & 0.74 \\
\hline Meropenem & 23 & 67.6 & 11 & 32.4 & 31 & 77.5 & 9 & 22.5 & 0.34 \\
\hline \multicolumn{10}{|l|}{ Blood } \\
\hline Ampicillin & 9 & 27.3 & 24 & 72.7 & 5 & 22.7 & 17 & 77.3 & 0.71 \\
\hline Ceftriaxone & 10 & 27.8 & 26 & 72.2 & 6 & 27.2 & 16 & 72.7 & 0.97 \\
\hline Ciprofloxacin & 11 & 61.1 & 7 & 38.9 & 10 & 58.8 & 7 & 41.2 & 0.89 \\
\hline Meropenem & 19 & 57.6 & 14 & 42.4 & 15 & 75.0 & 5 & 25.0 & 0.20 \\
\hline \multicolumn{10}{|l|}{ Urine } \\
\hline Ampicillin & 7 & 33.3 & 14 & 66.7 & 14 & 42.4 & 19 & 57.6 & 0.50 \\
\hline Ceftriaxone & 9 & 40.9 & 13 & 59.1 & 12 & 35.3 & 22 & 64.7 & 0.67 \\
\hline Ciprofloxacin & 9 & 56.3 & 7 & 43.8 & 15 & 88.2 & 2 & 11.8 & 0.06 \\
\hline Meropenem & 14 & 73.7 & 5 & 26.3 & 16 & 94.1 & 1 & 5.9 & 0.18 \\
\hline
\end{tabular}

$\mathrm{N}$ : number of susceptible or resistant results

Table 4 Susceptibility of pathogens in different infections for antibiotics commonly used in mono- or combination therapy

\begin{tabular}{|c|c|c|c|c|c|c|c|c|c|c|c|c|}
\hline \multirow[t]{3}{*}{ Antibiotic agent } & \multicolumn{4}{|c|}{ SBP } & \multicolumn{4}{|c|}{ BSI } & \multicolumn{4}{|c|}{ UTI } \\
\hline & \multicolumn{2}{|l|}{$\mathrm{S}$} & \multicolumn{2}{|l|}{$\mathbf{R}$} & \multicolumn{2}{|l|}{$S$} & \multicolumn{2}{|l|}{$\mathbf{R}$} & \multicolumn{2}{|l|}{$S$} & \multicolumn{2}{|l|}{$\mathbf{R}$} \\
\hline & $\mathrm{n}$ & $\%$ & $\mathrm{n}$ & $\%$ & $n$ & $\%$ & $\mathrm{n}$ & $\%$ & $\mathrm{n}$ & $\%$ & $\mathrm{n}$ & $\%$ \\
\hline Ampicillin/sulbactam & 51 & 60.7 & 33 & 39.3 & 31 & 56.4 & 24 & 43.6 & - & - & - & - \\
\hline Piperacillin/tazobactam & 55 & 65.5 & 29 & 34.5 & 30 & 53.6 & 26 & 46.4 & 36 & 65.5 & 19 & 34.5 \\
\hline Amoxicillin-/clavulanic acid & - & - & - & - & - & - & - & - & 12 & 46.2 & 14 & 53.8 \\
\hline Cefpodoxime & - & - & - & - & - & - & - & - & 18 & 40.0 & 27 & 60.0 \\
\hline Cefuroxime & 37 & 46.3 & 43 & 53.8 & 23 & 45.1 & 28 & 54.9 & - & - & - & - \\
\hline Ceftriaxone & 21 & 26.3 & 59 & 73.8 & 16 & 27.6 & 42 & 72.4 & 22 & 38.6 & 35 & 61.4 \\
\hline Fosfomycin & - & - & - & - & - & - & - & - & 15 & 88.2 & 2 & 11.8 \\
\hline Levofloxacin & - & - & - & - & - & - & - & - & 32 & 59.3 & 22 & 40.7 \\
\hline Ciprofloxacin & - & - & - & - & - & - & - & - & 25 & 73.5 & 9 & 26.5 \\
\hline Meropenem & 54 & 73.0 & 20 & 27.0 & 34 & 64.2 & 19 & 35.8 & 31 & 83.8 & 6 & 16.2 \\
\hline Vancomycin & 63 & 74.1 & 22 & 25.9 & 40 & 70.2 & 17 & 29.8 & - & - & - & - \\
\hline Cotrimoxazole & - & - & - & - & - & - & - & - & 27 & 48.2 & 29 & 51.8 \\
\hline Nitrofurantoin & - & - & - & - & - & - & - & - & 10 & 100 & 0 & 0.0 \\
\hline Ampicillin/sulbactam/vancomycin & 76 & 90.5 & 8 & 9.5 & 49 & 89.1 & 6 & 10.9 & 27 & 96.4 & 1 & 3.6 \\
\hline Piperacillin/tazobactam/vancomycin & 79 & 94.0 & 5 & 6.0 & 48 & 85.7 & 8 & 14.3 & 26 & 100 & 0 & 0.0 \\
\hline Meropenem/vancomycin & 73 & 100 & 0 & 0.0 & 52 & 98.1 & 1 & 1.9 & 8 & 100 & 0 & 0.0 \\
\hline Ceftriaxone/vancomycin & 72 & 91.1 & 7 & 8.9 & 52 & 92.9 & 4 & 7.1 & 26 & 96.3 & 1 & 3.7 \\
\hline
\end{tabular}

SBP spontaneous bacterial peritonitis, BSI bloodstream infection, UTI urinary tract infection, $n$ number of susceptible or resistant results, $S$ susceptible, $R$ resistant 
equally in both groups (nosocomial vs. communityacquired, $9.1 \%$ vs. $8.4 \%, p=0.94$ ). No major differences in resistances between community-acquired and nosocomial infections were found (Additional file 5: Table 5).

\section{Application of treatment guidelines}

To assess the effectivity of the EASL guidelines for the treatment of UTI, BSI or SBP at our center, we compared our local resistances with the EASL recommendations. For community-acquired SBP or septic UTI the recommended antibiotic regimen are 3rd generation cephalosporines or piperacillin/tazobactam [11]. In our cohort $61.3 \%$ of all culture-positive patients $(n=98$ of 160) had at least one pathogen resistant to ceftriaxone. This ratio was higher in patients with BSI $(71.4 \%, \mathrm{n}=35$ of 49$)$ and SBP $(66.7 \%, n=46$ of 69$)$ compared to patients with UTI $(43.2 \%, n=32$ of 74$)$. The ratio of culture-positive patients with at least one pathogen resistant to piperacillin/tazobactam was lower with $38.8 \%(n=62 / 160$, BSI: $51.0 \%, \mathrm{n}=25 / 49$; SBP: $36.2 \%, \mathrm{n}=25 / 69$; UTI: $24.3 \%$, $\mathrm{n}=18 / 74)$. Meropenem resistant pathogens were found in $23.1 \%$ culture-positive patients $(\mathrm{n}=37 / 160$, BSI; $36.7 \%$, $\mathrm{n}=18 / 49$, SBP: $24.6 \%, \mathrm{n}=17 / 69$, UTI: $8.1 \%, \mathrm{n}=6 / 74)$. In UTI the following ratios of patients with resistant pathogens were detected: ciprofloxacin $12.2 \%(n=22 / 74)$, cotrimoxazol $37.8 \% \quad(\mathrm{n}=28 / 74)$, nitrofurantoin $0.0 \%$ $(\mathrm{n}=0 / 74)$ and fosfomycin $2.7 \%(\mathrm{n}=2 / 74)$.

For nosocomial infection, combination therapy is recommended if risk factors are present, usually a carbapenem plus vancomycin, daptomycin, or linezolid. In our cohort, the combination therapy with meropenem plus vancomycin showed susceptibility in all patients with culture-positive SBP and UTI, except for one patient with BSI $(2.0 \%, n=1 / 49)$. Combination therapy with ampicillin/sulbactam plus vancomycin showed corresponding resistances in $11.6 \%$ of patients with culture-positive SBP $(n=8 / 69)$ and $12.2 \%$ in patients with BSI $(n=6 / 49)$. Therapy with piperacillin/tazobactam plus vancomycin had corresponding resistances in $16.3 \%$ of patients with BSI $(n=8 / 46), 7.2 \%$ of patients with culture-positive SBP $(\mathrm{n}=5 / 69)$ and $0.0 \%$ of patients with culture-positive UTI $(n=0 / 74)$. The combination of ceftriaxone plus vancomycin was affected by corresponding resistances in $7.5 \%$ $(n=12 / 160)$ of patients with culture-positive infections. The highest ratio was shown in patients with culturepositive SBP $(10.1 \%, \mathrm{n}=7 / 69)$ followed by BSI $(8.2 \%$, $\mathrm{n}=4 / 49)$ and UTI $(1.4 \%, \mathrm{n}=1 / 74)$.

\section{Discussion}

Cirrhosis is associated with a high frequency of infections, most notably SBP and UTI. To decrease resulting complications and mortality, early diagnosis and adequate empiric treatment based on the knowledge of local antibiotic resistances are necessary.

We here show that (1) a distinct ratio of infections was caused by gram-positive bacteria, (2) 3rd generation cephalosporins, commonly recommended as firstline therapy, were subject to a high ratio of antimicrobial resistance in our center, even in community-acquired infections, (3) the overall frequency of infections caused by MDR-bacteria was declining and resistance to meropenem was declining in particular and (4) other antibiotics seemed to be almost equally effective as meropenem even for the treatment of nosocomial infection, in particular, if combination therapy with vancomycin was applied.

In our study, the 90 -day mortality was $30.5 \%$ for patients with infection $(n=108 / 354)$. This ratio is a little bit lower compared to other studies, whereby there is a big range (1). The 90-day mortality differed according to the time of infection. Whereas patients with nosocomial infection showed a 90-day mortality of $34.4 \%$ $(n=99 / 288)$, the ratio was significantly lower for patients with community-acquired infection $(13.2 \%, \mathrm{n}=7 / 53$, $p=0.002)$.

Whereas in the past the majority of infections in cirrhotic patients were caused by gram-negative bacteria $[25,26]$, we currently observe a shift to the gram-positive bacteria. Several reasons have been linked to this shift: the more frequent use of invasive procedures [4], the frequent use of proton pump inhibitors (PPI) with a consecutive shift in intestinal microbiota [27], and alcohol intake with subsequent failure of the intestinal barrier and bacterial translocation [28]. In our cohort 542 patients $(81.4 \%)$ had PPI in their daily medication and 336 patients $(50.5 \%)$ had alcohol-related liver damage. However, no difference in ratios of gram-positive bacteria were found (ASH vs. non-ASH: $53.5 \%, \mathrm{n}=69 / 129$ vs. $54.5 \%, \mathrm{n}=72 / 132 ; p=0.86$. PPI vs. non-PPI: $54.3 \%$, $\mathrm{n}=127 / 234$ vs. $50.0 \%, \mathrm{n}=12 / 24 ; p=0.69)$. Gram-positive bacteria were especially frequent $(72.2 \%)$ in ascites which is in line with recent studies [15, 17, 29]. This is important to acknowledge as single antibiotic therapy will usually fail in our cohort, and the addition of vancomycin drastically increases the chances of effective antibiotic therapy. However, when interpreting these data, it has to be considered, that in some cases the detected pathogens belonged to the group of facultative pathogenic bacteria. Thus, we have to acknowledge, that the findings of e.g., certain gram-positive pathogens may be due to contamination in some cases while the true origin of infection is to be found elsewhere.

Third-generation cephalosporins are a first-line recommendation for community-acquired SBP [30, 31]. Our results showed high ratios of resistances against 
ceftriaxone in patients with SBP (73.8\%). Resistance was more frequent in nosocomial episodes $(75.0 \%)$ compared to community-acquired episodes (62.5\%) and increased over time by $28.0 \%$ (from $63.9 \%$ in period $1-81.8 \%$ in period $2, p=0.07$ ). This finding is in line with other recent reports [32-35]. Thus, special consideration should be given to the use of $3^{\text {rd }}$ generation cephalosporins according to local resistance profiles.

Resistance is usually higher in nosocomial infections than in community-acquired infections [18, 33]. We did not find a significant difference in resistances between these two groups. However, similar to the results of Umgelter et al. [32], the majority of patients $(81.4 \%$, $n=288 / 354$ ) in our study were classified as having a nosocomial infection. Other studies report lower rates [36, 37]. The high rate of nosocomial infection is well explained by the fact, that we provide tertiary care for patients with liver diseases. Thus, patients are more likely to be referred from other hospitals and tend to have more advanced liver disease (median MELD 17.6). The majority of classifications as nosocomial infection were caused by recent hospitalizations for various reasons-a common event in patients with decompensated cirrhosis [38]. Only 20 patients were directly admitted for infection, whereas the vast majority came to our hospital for ascitic decompensation or evaluation of transjugular intrahepatic portosystemic shunt placement or liver transplantation and infection was diagnosed on further work-up. It should be noted, that repeated hospitalization is a common event in cirrhotic patients. Therefore, per definition community-acquired infection may be caused by a different group of bacteria, which may influence resistance weights.

Based on our results first-line empiric therapy with piperacillin/tazobactam plus vancomycin for nosocomial SBP and UTI and meropenem plus vancomycin for nosocomial BSI might be the best choice for our center. However, this assumption can't simply be transferred to other hospitals due to regional differences in resistance prevalence.

Due to repeated hospitalizations and exposure to antibiotics, cirrhotic patients are increasingly challenged by MDR-infections [39]. Comparison between different studies is difficult due to inconsistent definitions of multiresistance. We used the definition of Magiorakos et al. [24] as well as specific resistances like oxacillin-resistance in Staphylococcus aureus to describe our cohort. Overall, 60 (31.3\%) of 192 culture-positive infections were caused by MDR-bacteria. This ratio was similar in all culture sites (SBP: $31.8 \%, \mathrm{n}=22 / 69$; BSI: $28.6 \%, \mathrm{n}=14 / 49$; UTI: $32.4 \%$, $\mathrm{n}=24 / 74)$ and is similar to results from other recent studies $[18,40]$. Compared to other German centers, we found no VRE in ascites during SBP $[35,41]$, despite high ratios of Enterococcus spp., and could not detect an increase of MDR-bacteria [42]. However, parts of the gram-positive pathogens must be considered as possible contamination. Analyzing only patients with possible MDR-bacteria (Enterobacteriaceae, Staphylococcus aureus, Enterococcus spp. or Acinetobacter spp.) the ratio of MDR-classified pathogens decreased over time (data not shown). In patients with gram-negative pathogens ratio of MDR-bacteria did not change over time (data not shown). Therefore, the missing increase of MDR-bacteria in this study can't be fully explained by contamination. For single antibiotics, the resistance against ceftriaxone was distinctly higher in our cohort [17, 29], whereas vancomycin resistance distinctly was lower [17]. In addition to local differences, some of the different findings may be explained by the time point of sampling, as antibiotic resistance may shift over time. Overall, the present data underline the recommendation to assess and track local rather than national resistance profiles.

In addition to the analyzed infections, pneumonia is common in patients with liver cirrhosis as well [2]. However, in this study cohort, respiratory material was infrequently collected or consisted mainly of sputum and the culture results were commonly positive for several bacteria of the oral flora. Unfortunately, these conditions were impeding analysis for patients with pneumonia.

This study has some limitations. First, it is based on retrospective data. As retrospective estimation of pathogenicity is difficult, we did not exclude pathogens that may be cultured due to contamination (i.e., coagulasenegative staphylococci, Corynebacterium, Propionibacterium, or Bacillus spp.). As mentioned before, this can partly explain the high ratio of gram-positive bacteria compared to other studies [33]. In addition, ratios of MDR-bacteria and other resistances could be stated too low due to including non-pathogenic germs. Second, there is a lack of microbiology sampling in many patients. Third, most patients had nosocomial infections by our definition, which makes the comparison between community-acquired and nosocomial infections difficult. Nevertheless, due to the large number of included patients and observed episodes of infections the results can help to adapt guidelines for empirical antibiotic treatment.

In conclusion, our study shows that (1) a distinct number of infections was caused by gram-positive bacteria, (2) 3rd generation cephalosporins had high ratios of antibiotic resistance at our center, (3) no increase in infections with MDR-bacteria occurred between 2012 and 2018, (4) for our center the first-line empiric therapy for patients with nosocomial SBP was sufficient with piperacillin/tazobactam, even despite declining resistances to meropenem. Thus, we can confirm the higher frequency 
of gram-positive pathogens with the consequence of gram-positive antibiotic coverage. However, our data shows a disparity for the first-line recommendation of third-generation cephalosporins in community-acquired infection and meropenem in nosocomial infections by the EASL guideline. Nevertheless, data regarding antibiotic resistance seems to show huge differences in different countries as well as in different clinics and regions of one country. Therefore, the results of this local study can't easily be transferred to other clinics or countries and local surveillance is strongly recommended.

\section{Abbreviations}

AST: Antibiotic susceptibility testing; BSI: Blood stream infection; CFU: Colony forming unit; EASL: European Association for the Study of the Liver; ECRDW: Enterprise clinical research data warehouse; EUCAST: European Committee on Antimicrobial Susceptibility Testing; HBV: Hepatitis B virus; HCC: Hepatocellular carcinoma; HCV: Hepatitis C virus; HIV: Human immunodeficiency virus; KRINKO: Commission of hospital hygiene and infection prevention; MDR: Multidrug-resistance; NASH: Nonalcoholic steatohepatitis; ORSA/MRSA: Oxacillin-/Methicillin-resistant Staphylococcus aureus; SBP: Spontaneous bacterial peritonitis; UTI: Urinary tract infection; 3MRGN: Multiresistant gram-negative germ.

\section{Supplementary Information}

The online version contains supplementary material available at https://doi. org/10.1186/s12876-021-01871-w.

Additional file 1.Supplemental table 1: Classification of multiresistant gram-negative bacilliform bacteria based on their phenotypic resistance characteristics.

Additional file 2. Supplemental table 2: Antimicrobial categories and agents used to define MDR.

Additional file 3. Supplemental table 3: Pathogens in polymicrobial infections.

Additional file 4. Supplemental table 4: Overview of the frequency and locations of infections.

Additional file 5. Supplemental table 5: Susceptibility of pathogens in community-acquired vs. nosocomial infections.

Acknowledgements

We thank all patients for their participation in this study, which helps us to provide better care.

\section{Authors' contributions}

Intellectual genesis: BM, CHZS. Data extraction and cleaning: AH, MS, TLT. Data analysis: AH, MS, TLT, SZ, CHZS, BM. Data interpretation: AH, CHZS, BM, SZ, RV, JR, MC, HW. Manuscript writing: AH, CHZS, BM, HW, MC. Critical manuscript review and editing: all authors. All authors read and approved the final manuscript.

\section{Funding}

Open Access funding enabled and organized by Projekt DEAL. No funding was received for the study.

\section{Availability of data and materials}

A data set sufficient to reproduce all main and supplementary figures is part of the manuscript or has been uploaded as supporting information. Due to ethical reasons, there are restrictions on sharing a complete data set of individual patients of this study publicly. The authors acknowledge the risk of private information being revealed by the public data disclosure, as the data underlying this study contain potentially identifiable and sensitive patient information. Therefore, the authors agreed that restrictions on sharing this study data should apply and data should be handled with care in order to protect the patients' confidentiality. Requests for access to a full de-identified data set of the study by qualified investigators can be addressed to the local ethics committee of Hannover Medical School (Ethikkommission@mh-hannover.de) or to the corresponding author.

\section{Declarations}

\section{Ethics approval and consent to participate}

The local ethics committee of Hannover Medical School approved the study (ethic no. 7935 BO_K_2018 from June 22nd 2018) and patients provided written informed consent for the scientific use of their clinical data. The study was conducted according to Declaration of Helsinki.

\section{Consent for publication}

Not applicable.

\section{Competing interests}

The authors declare that the research was conducted in the absence of any commercial or financial relationships that could be construed as a potential conflict of interest.

\section{Author details}

'Department for Gastroenterology, Hepatology and Endocrinology, Hannover Medical School, Carl-Neuberg-Str. 1, 30625 Hannover, Germany. ${ }^{2}$ Institute for Medical Microbiology and Hospital Epidemiology, Hannover Medical School, Hannover, Germany. ${ }^{3}$ Department of Respiratory Medicine, Hannover Medical School, Hannover, Germany. ${ }^{4}$ Antibiotic Stewardship, Hannover Medical School, Hannover, Germany. ${ }^{5}$ Center for Individualized Infection Medicine, Hannover Medical School, Hannover, Germany. ${ }^{6}$ Emergency Department, Hannover Medical School, Hannover, Germany. ${ }^{7}$ Centre for Infection Research (DZIF), partner site Hannover-Braunschweig, Braunschweig, Germany.

Received: 26 March 2021 Accepted: 8 July 2021

Published online: 20 July 2021

\section{References}

1. Arvaniti V, D'Amico G, Fede G, Manousou P, Tsochatzis E, Pleguezuelo $M$, et al. Infections in patients with cirrhosis increase mortality fourfold and should be used in determining prognosis. Gastroenterology. 2010;139(4):1246-55.

2. Fernández J, Gustot T. Management of bacterial infections in cirrhosis. J Hepatol. 2012;56:S1-12.

3. Schultalbers M, Tergast TL, Simon N, Kabbani A, Kimmann M, Zu Siederdissen $\mathrm{CH}$, et al. Frequency, characteristics and impact of multiple consecutive nosocomial infections in patients with decompensated liver cirrhosis and ascites. United European Gastroenterol J. 2020;8(5):567-76.

4. Fernández J, Navasa M, Gómez J, Colmenero J, Vila J, Arroyo V, et al. Bacterial infections in cirrhosis: epidemiological changes with invasive procedures and norfloxacin prophylaxis. Hepatology. 2002;35(1):140-8.

5. Foreman MG, Mannino DM, Moss M. Cirrhosis as a risk factor for sepsis and death: analysis of the National Hospital Discharge Survey. Chest. 2003:124(3):1016-20.

6. Kumar A, Haery C, Paladugu B, Kumar A, Symeoneides S, Taiberg L, et al. The duration of hypotension before the initiation of antibiotic treatment is a critical determinant of survival in a murine model of Escherichia coli septic shock: association with serum lactate and inflammatory cytokine levels. J Infect Dis. 2006;193(2):251-8.

7. Fernández J, Bauer TM, Navasa M, Rodés J. Diagnosis, treatment and prevention of spontaneous bacterial peritonitis. Baillieres Best Pract Res Clin Gastroenterol. 2000;14(6):975-90.

8. Ekpanyapong S, Reddy KR. Infections in cirrhosis. Curr Treat Options Gastroenterol. 2019;17(2):254-70.

9. Kim JJ, Tsukamoto MM, Mathur AK, Ghomri YM, Hou LA, Sheibani S, et al. Delayed paracentesis is associated with increased in-hospital mortality 
in patients with spontaneous bacterial peritonitis. Am J Gastroenterol. 2014;109(9):1436-42.

10. Fernández J, Navasa M, Planas R, Montoliu S, Monfort D, Soriano G, et al. Primary prophylaxis of spontaneous bacterial peritonitis delays hepatorenal syndrome and improves survival in cirrhosis. Gastroenterology. 2007;133(3):818-24.

11. Angeli P, Bernardi M, Villanueva C, Francoz C, Mookerjee RP, Trebicka J, et al. EASL Clinical Practice Guidelines for the management of patients with decompensated cirrhosis. J Hepatol. 2018;69(2):406-60.

12. Jalan R, Fernandez J, Wiest R, Schnabl B, Moreau R, Angeli P, et al. Bacterial infections in cirrhosis: a position statement based on the EASL Special Conference 2013. J Hepatol. 2014;60(6):1310-24.

13. Piano S, Singh V, Caraceni P, Maiwall R, Alessandria C, Fernandez J, et al. Epidemiology and effects of bacterial infections in patients with cirrhosis worldwide. Gastroenterology. 2019;156(5):1368-1380.e10

14. Fernández J, Prado V, Trebicka J, Amoros A, Gustot T, Wiest R, et al. Multidrug-resistant bacterial infections in patients with decompensated cirrhosis and with acute-on-chronic liver failure in Europe. J Hepatol. 2019;70(3):398-411.

15. Bert F, Andreu M, Durand F, Degos F, Galdbart J, Moreau R, et al. Nosocomial and community-acquired spontaneous bacterial peritonitis: comparative microbiology and therapeutic implications. Eur J Clin Microbiol Infect Dis. 2003;22(1):10-5.

16. Campillo B, Richardet J, Kheo T, Dupeyron C. Nosocomial spontaneous bacterial peritonitis and bacteremia in cirrhotic patients: impact of isolate type on prognosis and characteristics of infection. Clin Infect Dis. 2002;35(1):1-10.

17. Friedrich $K$, Nüssle S, Rehlen T, Stremmel W, Mischnik A, Eisenbach C. Microbiology and resistance in first episodes of spontaneous bacterial peritonitis: implications for management and prognosis. J Gastroenterol Hepatol. 2016:31(6):1191-5.

18. Fernández J, Acevedo J, Castro M, Garcia O, de Lope CR, Roca D, et al. Prevalence and risk factors of infections by multiresistant bacteria in cirrhosis: a prospective study. Hepatology. 2012;55(5):1551-61.

19. Park $Y H$, Lee $H C$, Song HG, Jung $S$, Ryu SH, Shin JW, et al. Recent increase in antibiotic-resistant microorganisms in patients with spontaneous bacterial peritonitis adversely affects the clinical outcome in Korea. $J$ Gastroenterol Hepatol. 2003;18(8):927-33.

20. Gerbes AL, Sauerbruch T, Dathe K. Method report: German S3-guideline "ascites, spontaneous bacterial peritonitis, hepatorenal syndrome." Z Gastroenterol. 2011;49(6):780-7.

21. Leitlinienprogramm DGU A. Interdisziplinäre S3 Leitlinie: Epidemiologie, Diagnostik, Therapie, Prävention und Management unkomplizierter, bakterieller, ambulant erworbener Harnwegsinfektionen bei erwachsenen Patienten. Langversion 1.1-2, 2017 AWMF Registernummer: 043/044. Available at: https://www.awmf.org/uploads/tx_szleitlinien/043-044l_S3_ Harnwegsinfektionen_2017-05.pdf. Accessed 27.10., 2020.

22. Nationales Referenzzentrum für Surveillance von nosokomialen Infektionen, Robert Koch-Institut. Definitionen nosokomialer Infektionen für die Surveillance im Krankenhaus-Infektions- Surveillance-System (KISSDefinitionen). 2017:6.

23. KRINKO. Hygienemaßnahmen bei Infektionen oder Besiedlung mit multiresistenten gramnegativen Stäbchen. Bundesgesundheitsblatt 2012;55:1311-54.

24. Magiorakos A-, Srinivasan A, Carey RB, Carmeli Y, Falagas ME, Giske CG, et al. Multidrug-resistant, extensively drug-resistant and pandrug-resistant bacteria: an international expert proposal for interim standard definitions for acquired resistance. Clin Microbiol Infect 2012;18(3):268-81.

25. Navasa M, Rimola A, Rodés J. Bacterial infections in liver disease. Semin Liver Dis. 1997:17(4):323-33.
26. Caly WR, Strauss E. A prospective study of bacterial infections in patients with cirrhosis. J Hepatol. 1993;18(3):353-8.

27. Wellhöner F, Döscher N, Tergast TL, Vital M, Plumeier I, Kahl S, et al. The impact of proton pump inhibitors on the intestinal microbiota in chronic hepatitis C patients. Scand J Gastroenterol. 2019;54(8):1033-41.

28. Yu L, Schwabe RF. The gut microbiome and liver cancer: mechanisms and clinical translation. Nat Rev Gastroenterol Hepatol. 2017;14(9):527-39.

29. Lutz P, Nischalke HD, Krämer B, Goeser F, Kaczmarek DJ, Schlabe S, et al. Antibiotic resistance in healthcare-related and nosocomial spontaneous bacterial peritonitis. Eur J Clin Invest. 2017;47(1):44-52.

30. Rimola A, García-Tsao G, Navasa M, Piddock LJ, Planas R, Bernard B, et al. Diagnosis, treatment and prophylaxis of spontaneous bacterial peritonitis: a consensus document. Int Ascites Club J Hepatol. 2000;32(1):142-53.

31. Căruntu FA, Benea L. Spontaneous bacterial peritonitis: pathogenesis, diagnosis, treatment. J Gastrointestin Liver Dis. 2006;15(1):51-6.

32. Umgelter A, Reindl W, Miedaner M, Schmid RM, Huber W. Failure of current antibiotic first-line regimens and mortality in hospitalized patients with spontaneous bacterial peritonitis. Infection. 2009:37(1):2-8.

33. Cheong HS, Kang C, Lee JA, Moon SY, Joung MK, Chung DR, et al. Clinical significance and outcome of nosocomial acquisition of spontaneous bacterial peritonitis in patients with liver cirrhosis. Clin Infect Dis. 2009;48(9):1230-6.

34. Angeloni S, Leboffe C, Parente A, Venditti M, Giordano A, Merli M, et al. Efficacy of current guidelines for the treatment of spontaneous bacterial peritonitis in the clinical practice. World J Gastroenterol. 2008;14(17):2757-62.

35. Ferstl PG, Müller M, Filmann N, Hogardt M, Kempf VA, Wichelhaus TA, et al. Noninvasive screening identifies patients at risk for spontaneous bacterial peritonitis caused by multidrug-resistant organisms. Infect Drug Resist. 2018;11:2047-61.

36. Navasa M, Follo A, Llovet JM, Clemente G, Vargas V, Rimola A, et al. Randomized, comparative study of oral ofloxacin versus intravenous cefotaxime in spontaneous bacterial peritonitis. Gastroenterology. 1996;111(4):1011-7

37. Toledo C, Salmerón JM, Rimola A, Navasa M, Arroyo V, Llach J, et al. Spontaneous bacterial peritonitis in cirrhosis: predictive factors of infection resolution and survival in patients treated with cefotaxime. Hepatology. 1993:17(2):251-7.

38. Volk ML, Tocco RS, Bazick J, Rakoski MO, Lok AS. Hospital readmissions among patients with decompensated cirrhosis. Am J Gastroenterol. 2012;107(2):247-52

39. Fernández J, Bert F, Nicolas-Chanoine M. The challenges of multi-drugresistance in hepatology. J Hepatol. 2016;65(5):1043-54.

40. Merli M, Lucidi C, Giannelli V, Giusto M, Riggio O, Falcone M, et al. Cirrhotic patients are at risk for health care-associated bacterial infections. Clin Gastroenterol Hepatol. 2010;8(11):979-85.

41. Mücke MM, Mayer A, Kessel J, Mücke VT, Bon D, Schwarzkopf K, et al. Quinolone and multidrug resistance predicts failure of antibiotic prophylaxis of spontaneous bacterial peritonitis. Clin Infect Dis. 2020;70(9):1916-24.

42. Li H, Wieser A, Zhang J, Liss I, Markwardt D, Hornung R, et al. Patients with cirrhosis and SBP: increase in multidrug-resistant organisms and complications. Eur J Clin Invest. 2020;50(2):e13198.

\section{Publisher's Note}

Springer Nature remains neutral with regard to jurisdictional claims in published maps and institutional affiliations. 